\title{
ChemComm
}

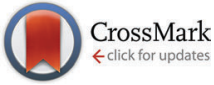

Cite this: Chem. Commun., 2016, 52,14238

Received 19th August 2016, Accepted 16th November 2016

DOI: $10.1039 / \mathrm{c} 6 \mathrm{cc} 06824 \mathrm{c}$

www.rsc.org/chemcomm

\section{Sequence-specific recognition of methylated DNA by an engineered transcription activator-like effector protein $\dagger$}

\author{
Shogo Tsuji, Shiroh Futaki and Miki Imanishi*
}

\begin{abstract}
A $5 \mathrm{mC}$-selective TALE-repeat was created by screening a TALE repeat library containing randomized amino acids at repeat variable diresidues and their neighboring residues. The new repeat showed high $5 \mathrm{mC}$ discrimination ability. An artificial TALE containing the new repeat activated an endogenous gene in a genomic methylation status-dependent manner.
\end{abstract}

DNA methylation is an important epigenetic marker that regulates gene expression, chromatin remodeling, and genome stability. ${ }^{1}$ DNA methylation status changes dynamically during development, cell cycle, and disease. ${ }^{2-4}$ In mammals, it occurs mainly at the cytosine base of $\mathrm{CpG}$ dinucleotides to produce 5-methylcytosine $(5 \mathrm{mC})$. To understand individual biological functions of locus-specific $5 \mathrm{mC}$, many different $5 \mathrm{mC}$ detection methods have been developed. However, sequence-specific $5 \mathrm{mC}$ detection methods in living cells, which allow us to understand the biological roles of methylation status at individual cytosine residues, are lacking. Bisulfite sequencing is one of the most powerful existing identification methods. ${ }^{5}$ This method reveals the genomic methylation status at single base resolution, but requires extraction of genomic DNA from cells. Thus, it is not applicable to living cells. Another approach is using anti-5mC antibodies or $5 \mathrm{mC}$ binding proteins to examine global DNA methylation levels. ${ }^{6-9}$ Although these approaches can observe the overall methylation status directly at the cellular level, antibodies or proteins employed in these methods are neither sequence-selective nor contain sequence constraints. Tools that recognize $5 \mathrm{mC}$ at a specific site without sequence constraints are needed.

Transcription activator-like effectors (TALEs) have attracted broad attention as designable DNA-binding scaffolds. ${ }^{10-12}$ Their DNA-binding specificity is determined by a series of tandem repeats of, typically, 34 highly conserved amino acids. Each repeat recognizes one target base. These repeats contain variable

Institute for Chemical Research, Kyoto University, Uji, Kyoto 611-0011, Japan. E-mail: imiki@scl.kyoto-u.ac.jp

$\dagger$ Electronic supplementary information (ESI) available. See DOI: 10.1039/c6cc06824c diresidues at positions 12 and 13, called repeat variable diresidues (RVD), which define the base preference of a repeat (Fig. 1A). Owing to the simple one-to-one base recognition of each repeat, TALEs can be readily designed to target specific DNA sequences by simply modifying the RVDs. An RVD recognizing $5 \mathrm{mC}$ but not $\mathrm{C}$ would provide useful TALEs that discriminate methylation status with designable sequence-specificity.

The commonly used RVD "NG" (Asn-Gly), specific for the thymine nucleobase, also binds to $5 \mathrm{mC}$ because of its structural similarity to thymine (Fig. 1A). ${ }^{13,14}$ Recently, using the RVD "NG", Kubik et al. showed that TALEs have the potential to differentiate $5 \mathrm{mC}$ from $\mathrm{C}$ at single base resolution. ${ }^{15-17}$ However, in these studies,

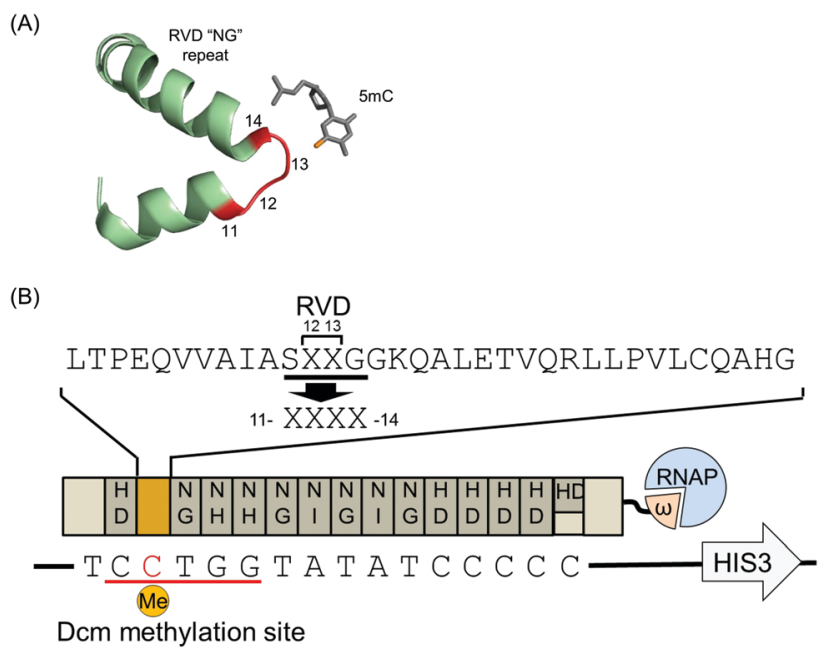

Fig. 1 Schematic representation of the bacterial one-hybrid screening for $5 \mathrm{mC}$-specific TALE repeats. (A) DNA recognition mode of a TALE repeat. The structure (PDB: 4GJP) shows an interaction between the RVD "NG" repeat and $5 \mathrm{mC}$. Four amino acid residues (11-14), including RVD, are shown in red. (B) The TALE- $\omega$ fusion protein targets the sequence containing Dcm methylated cytosine (red) on the promoter of the HIS3 reporter. The TALE contains 14.5 repeats with RVDs "NG", "HD", "NI", and "NH" for $\mathrm{T}$, $C, A$, and $G$ recognition, respectively. Target DNA sequences in the reporter vector are aligned to the TALE repeats. Four amino acid residues (11-14) of repeat 2 were randomized and are shown as XXXX. 
the methylation discrimination ability of TALEs was evaluated only by in vitro analysis. In cells, methylated DNA regions are often bound by $5 \mathrm{mC}$ binding proteins and tend to form heterochromatin that may inhibit TALEs from binding. It is necessary to evaluate the function of RVD "NG" in living cells. In addition, it has been reported that the methylation-discrimination ability of RVD “NG" is insufficient to completely regulate TALE binding in a methylation-dependent manner. ${ }^{17}$ Therefore, we searched for RVDs more specific to $5 \mathrm{mC}$ within living cells.

To search for non-native RVDs with the desired base preferences, comprehensive analyses of potential RVDs, which covered all 400 possible combinations of amino acid diresidues, were previously performed toward A, C, G, and T. ${ }^{18-20}$ However, in those studies, the specificities of those RVDs to $5 \mathrm{mC}$ were not evaluated. It is possible that there were RVDs that discriminate methylation of cytosine. On the other hand, in some molecular evolution studies of DNA-binding proteins, modification of residues that do not directly interact with DNA led to improved base preferences of the proteins. ${ }^{21-23}$ Taking into account these points, artificial TALE repeats with ideal $5 \mathrm{mC}$ preferences may be generated by modifying both RVD and their neighboring residues. In the current study, a TALE repeat library containing randomized amino acids at RVD and their neighboring residues was screened for $5 \mathrm{mC}$ selectivity, and a highly 5mC-selective repeat was successfully identified.

For the screening of new TALE repeats recognizing $5 \mathrm{mC}$, we developed a modified bacterial one-hybrid $(\mathrm{B} 1 \mathrm{H})$ screening that relied on the Dcm methylation system of $E$. coli, because of the integrity of the Dcm methylation system. Here, the binding of TALEs fused with the omega subunit of a bacterial RNA polymerase to the reporter vector allows the host $E$. coli to survive. $^{24}$ The E. coli Dcm methylation system was used to specifically methylate the cytosine base in the target sequence of the reporter vector. Most E. coli strains contain Dcm methylase that methylates the second cytosine in the sequences CCAGG and CCTGG. ${ }^{25}$ We designed a TALE that targeted the DNA sequence 5'-TCCTGGTATATCCCCC- $3^{\prime}$ containing a Dcm methylation site (underlined) and denoted it $\mathrm{TAL}_{\mathrm{Dcm}}$ (Fig. 1B). As expected, the reporter vectors extracted from the selection strain were not cleaved by a methylation-sensitive restriction enzyme, PspGI, targeting the sequence CCTGG (Fig. S1A, ESI $\dagger$ ). This suggested that the reporter vectors were methylated appropriately. Previous reports indicated that $\mathrm{N}$-terminal repeats were more sensitive to mismatches. ${ }^{26,27}$ Therefore, to maximize the effect of the repeat corresponding to $5 \mathrm{mC}$, the Dcm methylation site was placed at the $5^{\prime}$-end of the $\mathrm{TAL}_{\mathrm{Dcm}}$ target sequence. To select $5 \mathrm{mC}$-specific TALE repeats, a $\mathrm{TAL}_{\mathrm{Dcm}}$ library was generated by randomizing four residues (RVD and their neighboring residues) of repeat 2 that corresponded to Dcm methylated cytosine (Fig. 1B). Subsequent B1H screening gave several TALE repeats, but no specific sequence pattern was identified from the obtained mutants (Fig. S2, ESI $\dagger$ ). Therefore, the DNA binding preferences of all mutants were evaluated individually by luciferase reporter assays by expressing a $\mathrm{TAL}_{\mathrm{Dcm}}$-based transcription activator in HeLa cells. As reporter plasmids, $3 \times \mathrm{TAL}_{\mathrm{Dcm}}$ binding sites were inserted at the promoter of the luciferase gene, creating $3 \times \mathrm{TAL}_{\mathrm{Dcm}} / \mathrm{pGL}$. The plasmids were prepared using $\operatorname{Dcm}(-)$ and Dcm $(+)$ E. coli strains, resulting in an unmethylated and methylated status of the second cytosine bases in the $3 \times \mathrm{TAL}_{\mathrm{Dcm}}$ binding sites, respectively (Fig. S1B, ESI $\dagger$ ).

Initially, we evaluated the methylation discrimination ability of pre-existing RVDs. As expected, $\mathrm{TAL}_{\mathrm{Dcm}}$ with a C-specific RVD "HD" at repeat 2 showed significantly higher activity for $\mathrm{C}$ than for $5 \mathrm{mC}$. In contrast, comparable activation levels of the $\mathrm{C}$ and $5 \mathrm{mC}$ reporters were observed when using RVD "NG" at repeat 2 (Fig. S3A, ESI $\dagger$ ). These results are in good accordance with the results of an electrophoretic mobility shift assay (EMSA) (Fig. S3B, ESI $\dagger$ ), confirming that the discrimination ability of RVD "NG" is not always sufficiently high.

Next, the discrimination ability of all mutants selected from the $\mathrm{B} 1 \mathrm{H}$ screening for a methylated cytosine was assessed by luciferase reporter assays. Some mutants showed better discrimination ability than RVD "NG", but their activation levels were intolerably low (Fig. S4A, ESI $\dagger$ ). Intriguingly, the three mutants with "QSAA", "RNAA", or "RMAA" repeats, having the consensus sequence "XXAA", showed relatively high $5 \mathrm{mC}$ selectivity. Subsequently, we created an "XXAA" library and screened it by B1H screening. Several of the TALE repeats that were obtained showed a high ability to discriminate $5 \mathrm{mC}$ from C. Among them, the "ASAA" repeat showed the highest activity for the $5 \mathrm{mC}$ reporter (Fig. 2 and Fig. S4B, ESI $\dagger$ ). $\mathrm{TAL}_{\mathrm{Dcm}}$ with the "ASAA" repeat activated the luciferase gene in proportion to the methylation percentage of the reporter vectors (Fig. S5, ESI $\dagger$ ). This result indicates the methylation-dependent base recognition of the "ASAA" repeat.

The methylation discrimination ability of $\mathrm{TAL}_{\mathrm{Dcm}}$ with the "ASAA" repeat in living cells was confirmed by real-time monitoring of luciferase luminescence (Fig. S6, ESI $\dagger$ ). At each time point, luciferase activity was always higher in the cells transfected with the methylated compared to the unmethylated reporter. In addition, luciferase activity was greatly reduced for the reporter vector containing mutated $\mathrm{TAL}_{\mathrm{Dcm}}$ binding sites, indicating that introduction of the "ASAA" repeat does not impair the overall sequence-specificity of the original TALEs.

EMSAs also supported the methylation-discrimination ability of the "ASAA" repeat (Table 1). Specifically, TAL ${ }_{\text {Dcm }}$ with the "ASAA"

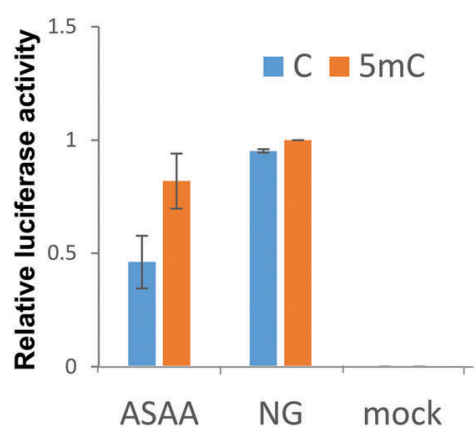

Fig. 2 Base specificity of the "ASAA" repeat. Luciferase reporter activities of $T A L_{D c m}$ having "ASAA" or RVD "NG" at repeat 2 for the reporter vectors with $C$ and $5 \mathrm{mC}$ binding sites (blue and orange, respectively). Luciferase activities were normalized to that of TAL $L_{\mathrm{Dcm}}$ with RVD "NG" for the $5 \mathrm{mC}$ reporter. 
Table $1 K_{d}$ values of $11.5 T A L_{D c m}{ }^{a}$ having "ASAA" or RVD "NG" at repeat 2

\begin{tabular}{llrl}
\hline & \multicolumn{2}{c}{$K_{\mathrm{d}}{ }^{b}(\mathrm{nM})$} & \\
\cline { 2 - 3 } Repeat 2 & $\mathrm{C}$ & \multicolumn{1}{c}{$5 \mathrm{mC}$} & Relative $K_{\mathrm{d}}(\mathrm{C} / 5 \mathrm{mC})$ \\
\hline ASAA & $235 \pm 10$ & $121 \pm 20$ & 1.9 \\
NG & $95 \pm 23$ & $74 \pm 36$ & 1.2
\end{tabular}

${ }^{a}$ Because of the difficulty in purifying the proteins, EMSAs were performed using $11.5 \mathrm{TAL}_{\mathrm{Dcm}}$ obtained by truncating three C-terminal repeats from $\mathrm{TAL}_{\mathrm{Dcm}} \cdot{ }^{b}$ Determined by EMSA.

repeat showed 1.9-fold stronger binding to $5 \mathrm{mC}$ than $\mathrm{C}$, whereas TAL $_{\text {Dcm }}$ with the RVD "NG" repeat showed 1.2-fold stronger binding, although the dissociation constant of $\mathrm{TAL}_{\mathrm{Dcm}}$ with the "ASAA" repeat for $5 \mathrm{mC}$ was higher than that with the RVD "NG" repeat.

In mammals, cytosine methylation mainly occurs at $\mathrm{CpG}$ dinucleotide sites. Therefore, to verify whether the "ASAA" repeat could also recognize $5 \mathrm{mC}$ within the $\mathrm{CpG}$ context, we designed a TALE that targeted a CPG methylation sequence (Fig. S7A, ESI $\dagger$ ). EMSAs showed that the TALE with the "ASAA" repeat had a lower dissociation constant for the $5 \mathrm{mC}$ target than for $\mathrm{C}$, while the TALE with the RVD "NG" repeat instead of the "ASAA" repeat had comparable dissociation constants between $5 \mathrm{mC}$ and $\mathrm{C}$ targets (Table 2). These results indicate that the "ASAA" repeat also preferentially recognizes $5 \mathrm{mC}$ within the CpG context, and that the discrimination ability of the "ASAA" repeat is higher than that of the RVD "NG" repeat. Unfortunately, a TALE with two "ASAA" repeats failed to preferentially bind to the target DNA containing two 5mC (Fig. S7B and C, ESI $\dagger$ ). This may be because the affinity of the "ASAA" repeat to $5 \mathrm{mC}$ is not very strong.

Finally, we explored the ability of the "ASAA" repeat to regulate endogenous gene expression dependent on the methylation status of genomic DNA. A TALE targeting an endogenous gene, Ras association domain-containing protein 2 (RASSF2), was designed and denoted $\mathrm{TAL}_{\mathrm{RASSF} 2}$. RASSF2 works as a tumor suppressor gene and the RASSF2 protein induces apoptosis in tumor cells. ${ }^{28,29}$ In many colorectal tumor cell lines, the promoter region of $R A S S F 2$ is highly methylated and thus RASSF2 hypermethylation is a potential marker for cancer diagnosis. ${ }^{30}$ SW480 and HCT116 cells were reported to have different RASSF2 methylation statuses. ${ }^{28}$ Bisulfite sequencing showed that RASSF2 was highly methylated in SW480 but not in HCT116 cells (Fig. S8, ESI $\dagger$ ). TAL RASSF2, which targets the RASSF2 promoter region including CpG dinucleotides, was fused to a transcription activator, p300 histone acetyltransferase, to activate RASSF2 by binding $\mathrm{TAL}_{\mathrm{RASSF} 2}$ to the target genomic region (Fig. 3A). TAL $\mathrm{RASSF}_{2}$-p300 was expressed in

Table $2 K_{d}$ values of TALEs having "ASAA" or RVD "NG" at repeat 3 to the target sequence containing $\mathrm{C}$ or $5 \mathrm{mC}$ at the $\mathrm{CpG}$ site

\begin{tabular}{llll}
\hline & \multicolumn{2}{l}{$K_{\mathrm{d}}{ }^{a}(\mu \mathrm{M})$} & \\
\cline { 2 - 3 } Repeat 3 & $\mathrm{C}$ & $5 \mathrm{mC}$ & Relative $K_{\mathrm{d}}(\mathrm{C} / 5 \mathrm{mC})$ \\
\hline ASAA & $2.3 \pm 0.2$ & $1.5 \pm 0.2$ & 1.6 \\
NG & $0.9 \pm 0.1$ & $0.8 \pm 0.1$ & 1.1 \\
\multicolumn{2}{l}{ Determined by EMSA. } & &
\end{tabular}

(A)

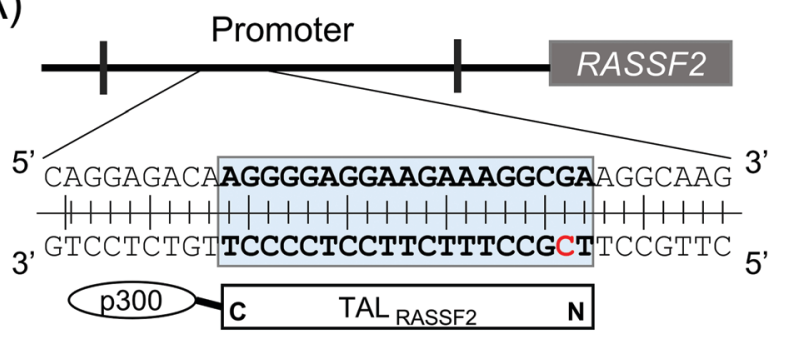

(B)
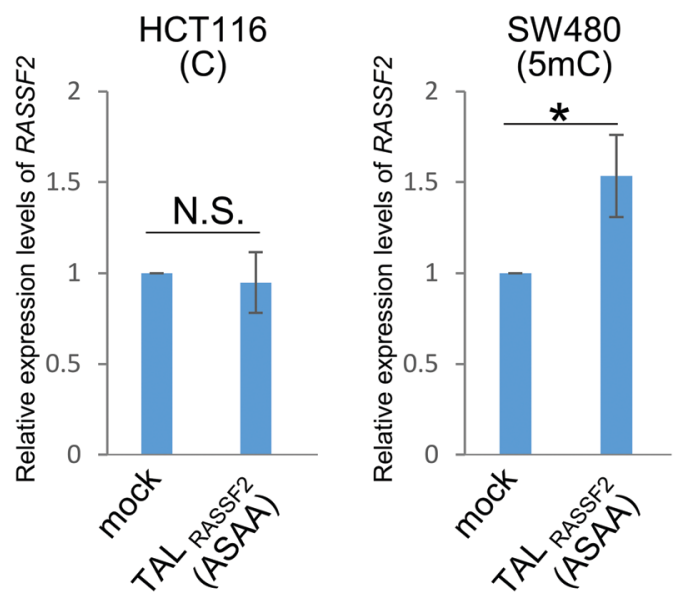

Fig. 3 Methylation status-dependent activation of an endogenous gene by $\mathrm{TAL}_{\text {RASSF2 }}-\mathrm{p} 300$. (A) Design of $\mathrm{TAL}_{\mathrm{RASSF} 2}-\mathrm{p} 300$ that targets the RASSF2 promoter region. The target sequence of TAL $\mathrm{RASSF}_{2}$ is highlighted with light blue. Target $5 \mathrm{mC}$ is colored in red. (B) Twenty-four $h$ after TAL RASSF2 $-\mathrm{p} 300$ ("ASAA") transfection, relative expression levels of RASSF2 mRNA in HCT116 and SW480 cells were examined by RT-qPCR. The expression levels were normalized to those of GAPDH. Data are expressed as means \pm SD. $n=3$; ${ }^{*} P<0.05$

SW480 and HCT116 cells, and the expression levels of RASSF2 mRNA were evaluated by RT-qPCR. When using the "ASAA" repeat, significant gene activation was induced only in SW480 cells that had a highly methylated RASSF2 promoter (Fig. 3B). This result was not due to differences of cell types or chromatin states because TAL $\mathrm{RASSF}_{2}$ with the RVD "NG" repeat instead of the "ASAA" repeat activated the gene in both cell types (Fig. S9, ESI $\dagger$ ). Therefore, the result suggested that the "ASAA" repeat contributed to the selective binding to $5 \mathrm{mC}$.

In conclusion, we successfully created a highly $5 \mathrm{mC}$-selective TALE repeat by Dcm methylation-dependent B1H screening of the TALE library. The new repeat showed high $5 \mathrm{mC}$ discrimination ability even for genomic DNA. One reason for the successful screening targeting $5 \mathrm{mC}$ may be the expanded randomization strategy. Although further improvement of the affinity is desired, the new repeat enabled us to use TALEs as an easily designable tool to detect $5 \mathrm{mC}$ at user-defined sites in living cells. For example, fluorescently labeled TALE has been used to visualize endogenous sequences to study chromatin dynamics. ${ }^{31,32}$ Using $5 \mathrm{mC}$-selective TALEs, time-lapse observations of the methylation status at specific sites can be realized. Furthermore, TALEs have been used as artificial transcriptional regulators, nucleases, and epigenetic modulators. ${ }^{33-35}$ Thus, methylation status-dependent 
gene regulation is possible using the $5 \mathrm{mC}$-selective TALE repeat in contrast to the existing $5 \mathrm{mC}$ identification methods. In addition, there are many kinds of modified nuclear bases besides $5 \mathrm{mC} .^{36,37}$ Our strategy to obtain new functional TALE repeats is applicable to other modified nuclear bases. This study should provide new ways of exploring the biological functions of $5 \mathrm{mC}$ and other modified nuclear bases.

We thank Feng Zhang for the plasmids used to construct the TALEs, Warner Greene for plasmids, Scot Wolfe for plasmids and cells for B1H screening, and Hiromu Suzuki for the SW480 and HCT116 cells. This work was supported in part by JSPS KAKENHI 16H03281 (M. I.) and 15J09770 (S. T.), JST CREST and the Naito Foundation.

\section{Notes and references}

1 J. A. Law and S. E. Jacobsen, Nat. Rev. Genet., 2010, 11, 204.

2 Z. D. Smith and A. Meissner, Nat. Rev. Genet., 2013, 14, 204.

3 S. E. Brown, M. F. Fraga, I. C. G. Weaver, M. Berdasco and M. Szyf, Epigenetics, 2007, 2, 54.

4 G. Egger, G. Liang, A. Aparicio and P. A. Jones, Nature, 2004, 429, 457.

5 S. J. Cokus, S. Feng, X. Zhang, Z. Chen, B. Merriman, C. D. Haudenschild, S. Pradhan, S. F. Nelson, M. Pellegrini and S. E. Jacobsen, Nature, 2008, 452, 215.

6 F. Santos, B. Hendrich, W. Reik and W. Dean, Dev. Biol., 2002, $241,172$.

7 S. Kobayakawa, K. Miike, M. Nakao and K. Abe, Genes Cells, 2007, $12,447$.

8 C. Desjobert, M. E. Maï, T. Gérard-Hirne, D. Guianvarc'h, A. Carrier, C. Pottier, P. B. Arimondo and J. Riond, Epigenetics, 2015, 10, 82.

9 S. Celik-Uzuner, Y. Li, L. Peters and C. O'Neill, In Vitro Cell. Dev. Biol.: Anim., DOI: 10.1007/s11626-016-0075-4.

10 J. Boch, H. Scholze, S. Schornack, A. Landgraf, S. Hahn, S. Kay, T. Lahaye, A. Nickstadt and U. Bonas, Science, 2009, 326, 1509.

11 A. J. Bogdanove and D. F. Voytas, Science, 2011, 333, 1843.

12 T. Gaj, C. A. Gersbach and C. F. Barbas, Trends Biotechnol., 2013, 31, 397.

13 D. Deng, P. Yin, C. Yan, X. Pan, X. Gong, S. Qi, T. Xie, M. Mahfouz, J. K. Zhu, N. Yan and Y. Shi, Cell Res., 2012, 22, 1502.

14 J. Valton, A. Dupuy, F. Daboussi, S. Thomas, A. Marechal, R. Macmaster, K. Melliand, A. Juillerat and P. Duchateau, J. Biol. Chem., 2012, 287, 38427.

15 G. Kubik, M. J. Schmidt, J. E. Penner and D. Summerer, Angew. Chem., Int. Ed., 2014, 53, 6002.

16 G. Kubik and D. Summerer, ChemBioChem, 2015, 16, 228.

17 G. Kubik, S. Batke and D. Summerer, J. Am. Chem. Soc., 2015, 137, 2.

18 J. Yang, Y. Zhang, P. Yuan, Y. Zhou, C. Cai, Q. Ren, D. Wen, C. Chu, H. Qi and W. Wei, Cell Res., 2014, 24, 628.
19 A. Juillerat, C. Pessereau, G. Dubois, V. Guyot, A. Marechal, J. Valton, F. Daboussi, L. Poirot, A. Duclert and P. Duchateau, Sci. Rep., 2015, $5,8150$.

20 J. C. Miller, L. Zhang, D. F. Xia, J. J. Campo, I. V. Ankoudinova, D. Y. Guschin, J. E. Babiarz, X. Meng, S. J. Hinkley, S. C. Lam, D. E. Paschon, A. I. Vincent, G. P. Dulay, K. A. Barlow, D. A. Shivak, E. Leung, J. D. Kim, R. Amora, F. D. Urnov, P. D. Gregory and E. J. Rebar, Nat. Methods, 2015, 12, 465.

21 S. Tsuji, S. Futaki and M. Imanishi, Biochem. Biophys. Res. Commun., 2013, 441, 26.

22 B. M. Lamb, A. C. Mercer and C. F. Barbas, Nucleic Acids Res., 2013, 41, 9779.

23 B. P. Hubbard, A. H. Badran, J. A. Zuris, J. P. Guilinger, K. M. Davis, L. Chen, S. Q. Tsai, J. D. Sander, J. K. Joung and D. R. Liu, Nat. Methods, 2015, 12, 939.

24 M. B. Noyes, X. Meng, A. Wakabayashi, S. Sinha, M. H. Brodsky and S. A. Wolfe, Nucleic Acids Res., 2008, 36, 2547.

25 B. R. Palmer and M. G. Marinus, Gene, 1994, 143, 1.

26 J. F. Meckler, M. S. Bhakta, M.-S. Kim, R. Ovadia, C. H. Habrian, A. Zykovich, A. Yu, S. H. Lockwood, R. Morbitzer, J. Elsaesser, T. Lahaye, D. J. Segal and E. P. Baldwin, Nucleic Acids Res., 2013, 41, 4118.

27 A. Juillerat, G. Dubois, J. Valton, S. Thomas, S. Stella, A. Marechal, S. Langevin, N. Benomari, C. Bertonati, G. H. Silva, F. Daboussi, J. C. Epinat, G. Montoya, A. Duclert and P. Duchateau, Nucleic Acids Res., 2014, 42, 5390.

28 K. Akino, M. Toyota, H. Suzuki, H. Mita, Y. Sasaki, M. Ohe-Toyota, J. P. J. Issa, Y. Hinoda, K. Imai and T. Tokino, Gastroenterology, 2005, 129, 156.

29 W. N. Cooper, L. B. Hesson, D. Matallanas, A. Dallol, A. von Kriegsheim, R. Ward, W. Kolch and F. Latif, Oncogene, 2009, 28, 2988.

30 J. Shi, G. Zhang, D. Yao, W. Liu, N. Wang, M. Ji, N. He, B. Shi and P. Hou, Am. J. Cancer Res., 2012, 2, 116.

31 Y. Miyanari, C. Z. Birling and M. E. T. Padilla, Nat. Struct. Mol. Biol., 2013, 20, 1321.

32 H. Ma, P. Reyes-Gutierrez and T. Pederson, Proc. Natl. Acad. Sci. U. S. A., 2013, 110, 21048.

33 J. Hu, Y. Lei, W.-K. Wong, S. Liu, K.-C. Lee, X. He, W. You, R. Zhou, J.-T. Guo, X. Chen, X. Peng, H. Sun, H. Huang, H. Zhao and B. Feng, Nucleic Acids Res., 2014, 42, 4375.

34 V. M. Bedell, Y. Wang, J. M. Campbell, T. L. Poshusta, C. G. Starker, R. G. Krug, W. Tan, S. G. Penheiter, A. C. Ma, A. Y. H. Leung, S. C. Fahrenkrug, D. F. Carlson, D. F. Voytas, K. J. Clark, J. J. Essner and S. C. Ekker, Nature, 2012, 491, 114.

35 M. L. Maeder, J. F. Angstman, M. E. Richardson, S. J. Linder, V. M. Cascio, S. Q. Tsai, Q. H. Ho, J. D. Sander, D. Reyon, B. E. Bernstein, J. F. Costello, M. F. Wilkinson and J. K. Joung, Nat. Biotechnol., 2013, 31, 1137.

36 M. Tahiliani, K. P. Koh, Y. Shen, W. A. Pastor, H. Bandukwala, Y. Brudno, S. Agarwal, L. M. Iyer, D. R. Liu, L. Aravind and A. Rao, Science, 2009, 324, 930.

37 S. Ito, L. Shen, Q. Dai, S. C. Wu, L. B. Collins, J. A. Swenberg, C. He and Y. Zhang, Science, 2011, 333, 1300. 